\title{
Regurgitation of a mass into the mouth: a fibrovascular polyp of the esophagus
}

A 45-year-old man visited our hospital with a 6-month history of intermittent regurgitation of a mass into his mouth. Laryngoscopy revealed a smooth mass in the pharynx; this mass had prolapsed from the esophagus $(\bullet$ Fig. $\mathbf{1}$ a, b).

Esophagogastroduodenoscopy revealed a sausage-shaped pedunculated mass covered with normal esophageal epithelium arising from the cervical esophagus just below the cricopharyngeus muscle and extending up to $25 \mathrm{~cm}$ distal to the incisor $(\bullet$ Fig. $2 \mathrm{a}-\mathrm{c}$ ).

The T1- and T2-weighted magnetic resonance images showed a hyperintense mass, and a T2-weighted image with fat suppression showed a drop in signal intensity ( $\bullet$ Fig. 3a-c).

Transoral resection was performed under general anesthesia by direct visualization (๑ Fig. 4).

Histologic studies showed that the polyp had fibrous and vascular components as well as adipose tissue covered with normal squamous epithelium ( $\bullet$ Fig. 5).

Fibrovascular polyps (FVPs) of the esophagus are rare benign tumors that are typically large and pedunculated and arise from the cervical esophagus [1]. A previous study reported that $75 \%$ of these polyps were $7 \mathrm{~cm}$ or longer at the time of presentation $[1,2]$. In the past, FVPs have been referred to as fibromas, fibrolipomas, myxofibromas, and pedunculated lipomas, depending on the major component. However, the World Health Organization recommends that all these types be grouped together as FVPs. Magnetic resonance imaging is useful for characterizing polyp components. Although patients with such polyps often present with dysphagia, there are some reports of serious and potentially fatal complications, including sudden death due to asphyxiation secondary to regurgitation into the mouth [3-5]. Some clinicians may disregard a patient's complaint of regurgitation of a mass; however, as this can be an imminent sign of the presence of a potentially fatal polyp, careful examination, accurate diagnosis, and early intervention are mandatory.

Competing interests: None

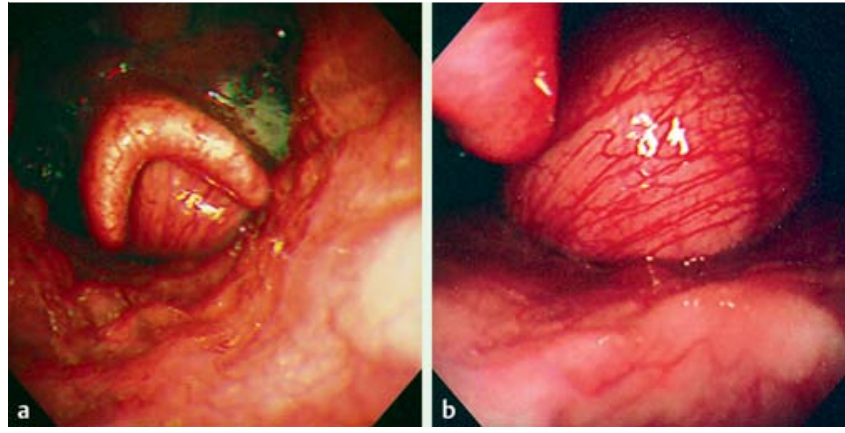

Fig. 1 Laryngoscopy reveals a mass in the mouth. a Distant view; b near view.

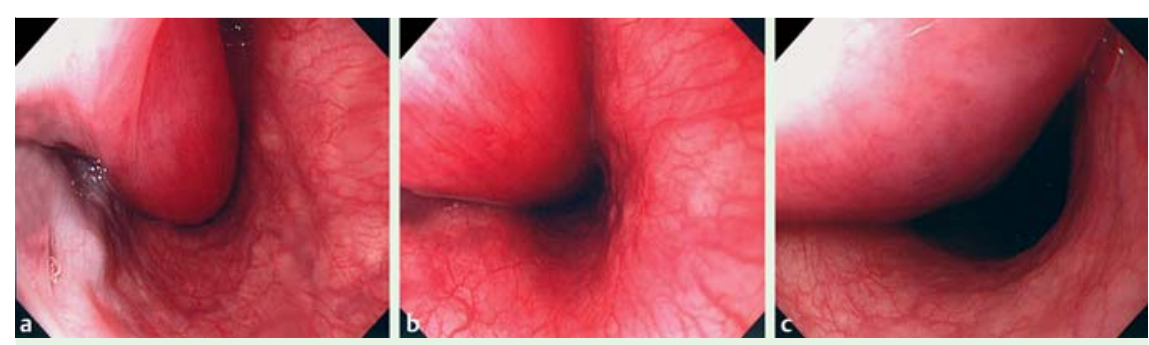

Fig. 2 Esophagogastroduodenoscopy shows a large pedunculated polyp covered with normal squamous epithelium. a Area of origin of the stalk; $\mathbf{b}$ long stalk; $\mathbf{c}$ head of the polyp.
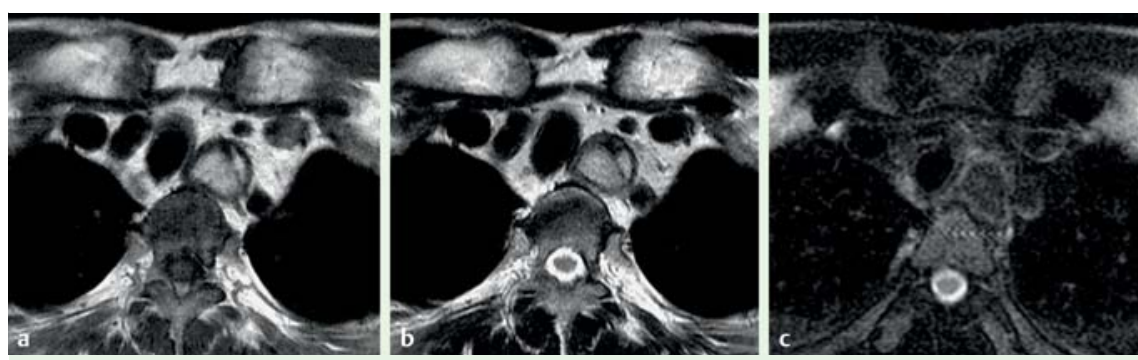

Fig. 3 Magnetic resonance imaging shows a hyperintense mass in the esophagus. a T1-weighted image; b T2-weighted image; c T2-weighted image with fat suppression shows a drop in signal intensity.

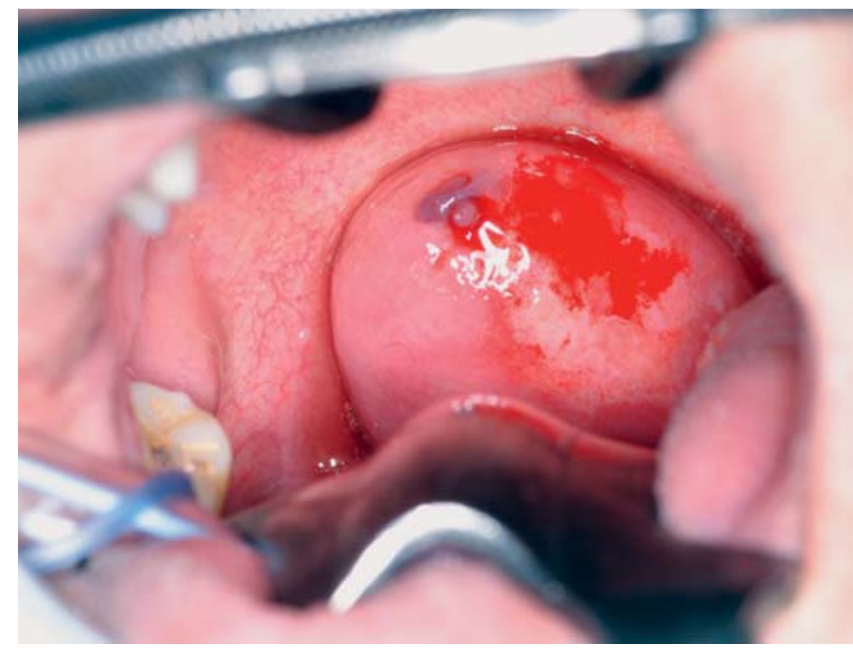

Fig. 4 Intraoperative examination under general anesthesia shows a large mass in the pharynx. 


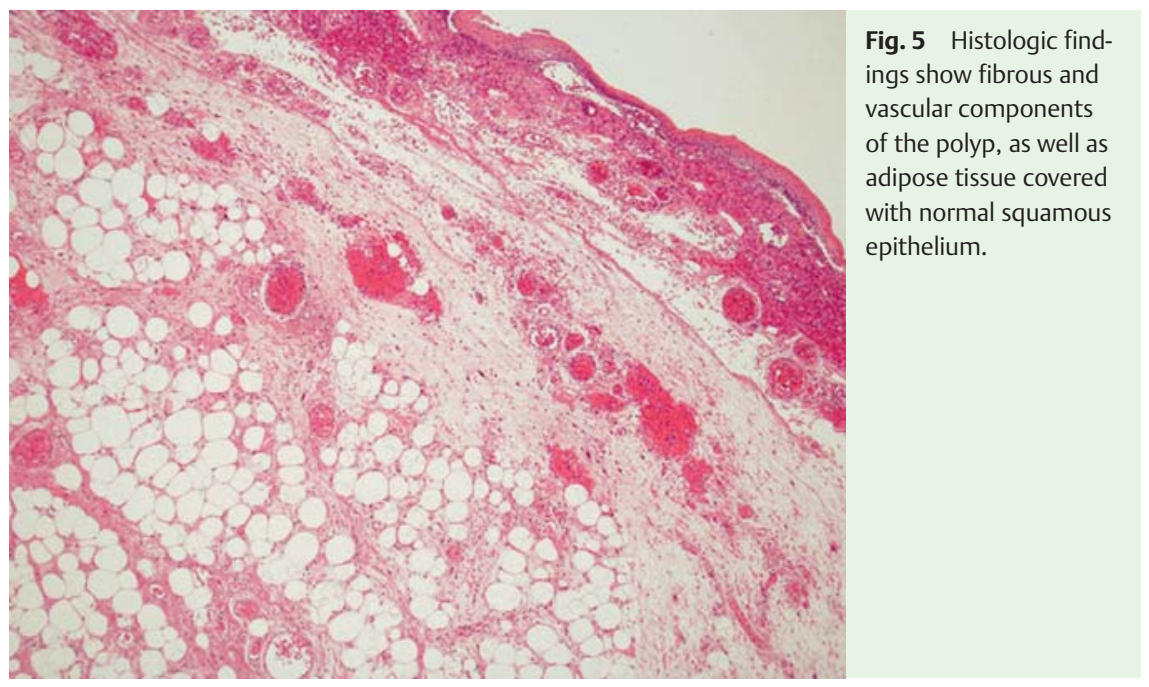

Endoscopy_UCTN_Code_CCL_1AB_2AC_3AB

A. Goto ${ }^{1}$, M. Suzuki², K. lizuka², Y. Yoshida ${ }^{3}$, K. Suzuki ${ }^{1}$, M. Itoh ${ }^{1}$, H. Wakasugi ${ }^{1}$, K. Fujii ${ }^{1}$, Y. Matunaga ${ }^{1}$, Y. Shinomura ${ }^{4}$

1 Department of Gastroenterology, Kushiro City General Hospital, Kushiro, Japan

\section{References}

1 Caceres M, Steeb G, Wilks SM et al. Large pedunculated polyps originating in the esophagus and hypopharynx. Ann Thorac Surg 2006; 81: 393-696

2 Behar PM, Arena S, Marrangoni AG. Recurrent fibrovascular polyp of the esophagus. Am J Otolaryngol 1995; 16: 209-212

3 Allen MS Jr., Talbot WH. Sudden death due to regurgitation of a pedunculated esophageal lipoma. J Thorac Cardiovasc Surg 1967; 54 : $756-758$

4 Fries MR, Galindo RL, Flint PW et al. Giant fibrovascular polyp of the esophagus. A lesion causing upper airway obstruction and syncope. Arch Pathol Lab Med 2003; 127: 485- 487

5 Sargent RL, Hood IC. Asphyxiation caused by giant fibrovascular polyp of the esophagus. Arch Pathol Lab Med 2006; 130: 725 - 727

\section{Bibliography}

DOI $10.1055 / \mathrm{s}-0030-1255618$

Endoscopy 2010; 42: E248 -E249

(c) Georg Thieme Verlag KG Stuttgart · New York . ISSN 0013-726X

\section{Corresponding author}

\section{A. Goto, MD}

Department of Gastroenterology

Kushiro City General Hospital

1-12 Shunkodai

Kushiro 085-0822

Japan

Fax: +81-0154-414080

goa@sapmed.ac.jp 